\title{
Efeito dos níveis de concentrado sobre os componentes não-carcaça de ovinos Morada Nova em confinamento ${ }^{1}$
}

\section{Geovergue Rodrigues de Medeiros ${ }^{2^{*}}$, Francisco Fernando Ramos de Carvalho ${ }^{3}$, Marcelo de Andrade Ferreira ${ }^{3}$, Kaliandra Souza Alves ${ }^{2,4}$, Carla Wanderley Mattos ${ }^{2}$, Tibério de Albuquerque Saraiva ${ }^{2}$, Jansen Ferreira do Nascimento ${ }^{5}$}

\author{
1 Projeto financiado pela FACEPE/CNPq. \\ 2 Pós-graduação em Zootecnia - UFRPE. \\ ${ }^{3}$ Departamento de Zootecnia - UFRPE - Recife - PE. \\ ${ }^{4}$ Curso de Graduação em Zootecnia, Unidade Descentralizada de Parauapebas - UDP/UFRA/Carajás. \\ ${ }^{5}$ Graduação em Zootecnia - UFRPE - Recife-PE.
}

RESUMO - Objetivou-se avaliar os pesos e rendimentos de órgãos, vísceras, subprodutos e componentes comestíveis de 32 ovinos da raça Morada Nova, castrados, confinados, recebendo dietas contendo 20; 40; 60 e 80\% de concentrado. Os animais $(8,11 \pm 1,15$ meses de idade e $19,67 \pm 2,97 \mathrm{~kg}$ de peso inicial) foram abatidos aos 30,0 kg. Utilizou-se delineamento experimental em blocos casualizados, com quatro tratamentos e oito repetições. O aumento dos níveis de concentrado elevou os pesos de corpo vazio (25,12; 25,69; 25,87 e 26,82 kg), fígado (0,497;0,565; 0,566 e 0,653 kg), vesícula biliar (0,009; 0,014; 0,020 e $0,033 \mathrm{~kg})$, intestino delgado $(0,460 ; 0,564 ; 0,582$ e $0,650 \mathrm{~kg})$, sangue $(1,258 ; 1,363 ; 1,295$ e $1,597 \mathrm{~kg})$, pele $(1,944 ; 1967 ; 1,991$ e 2,236), patas $(0,607 ; 0,623 ; 0,620$ e 0,692 kg), miúdos da "buchada" (4,489; 4,602; 4,750 e $5,055 \mathrm{~kg}$ ) e seus rendimentos em relação ao peso corporal ao abate (14,51; 14,75; 15,50 e 16,29\%), mas reduziu linearmente o conteúdo do trato gastrintestinal $(5,80 ; 5,47 ; 4,80$ e $4,16 \mathrm{~kg})$ e do omaso $(0,089 ; 0,070 ; 0,063$ e $0,058 \mathrm{~kg})$. Os pesos e rendimentos de alguns órgãos, vísceras, subprodutos e gorduras internas não foram alterados pelos planos nutricionais. Independentemente dos níveis de concentrado utilizados, os pesos e rendimentos dos componentes não-carcaça foram altos, com valores que refletem diretamente em menores pesos e rendimentos da carcaça dos ovinos Morada Nova confinados.

Palavras-chave: buchada, dieta, órgãos, peso ao abate, subprodutos, vísceras

\section{Effect of concentrate levels on non carcass components of the Morada Nova hair sheep in feedlot}

ABSTRACT - The objective of this study was evaluate the yields and weights of the organs, viscera, by-products and edible offal in 32 males castrate Morada Nova hair sheep breed, in feedlot, fed with diets containing 20.040 .060 .0 and $80.0 \%$ of concentrate. The animals (8.11 \pm 1.15 months old, $19.67 \pm 2.97 \mathrm{~kg} \mathrm{BW})$ were slaughtered at $30.0 \mathrm{~kg}$ BW. A completely randomized blocks design, with four diets and eight replicates, was used. The crescent concentrate levels increased empty body weight (25.12, 25.69, 25.87, and $26.82 \mathrm{~kg})$, liver $(0.497,0.565,0.566$, and $0.653 \mathrm{~kg})$, gall bladder $(0.009,0.014,0.020$, and $0.033 \mathrm{~kg})$, small intestine $(0.460,0.564,0.582$, and $0.650 \mathrm{~kg})$, blood $(1.258,1.363,1.295$, and $1.597 \mathrm{~kg})$, paws $(0.607,0.623$, 0.620 , and $0.692 \mathrm{~kg})$, "buchada” offals $(4.489,4.602,4.750$, and $5.055 \mathrm{~kg})$ and their yields in relation to slaughter body weight (14.51, 14.75, 15.50, and 16.29\%), while there was linear decreasing for digestive tract content $(5.80,5.47,4.80$, and $4.16 \mathrm{~kg}$ ) and omasum $(0.089,0.070,0.063$, and $0.058 \mathrm{~kg})$. No treatment effect on weights and yields of some organs, viscera, byproducts and internal fats was observed. Beyond the used concentrate levels, the yields and weights of non carcass components were high, with values that directly reflect in less yields and weights of carcass of the feedlot Morada Nova hair sheep.

Key Words: by-products, diet, edible offal, organs, slaughter weight, viscera

\section{Introdução}

É fato que o atual cenário da ovinocultura nacional, aliado às exigências do mercado consumidor, está direcionado para a intensificação da produção e aumento em termos quantitativos e qualitativos de carcaças ovinas.

O confinamento de ovinos tem sido estimulado, mas, para obtenção de ganhos que compensem economicamente essa prática, a dieta deverá conter níveis adequados

Este artigo foi recebido em 8/5/2006 e aprovado em 17/12/2007.

* Endereço atual: Instituto Nacional do Semi-Árido (INSA). 
de proteína e altos de energia, com ocorrência da maximização do uso de concentrados. Por outro lado, a comercialização de ovinos para corte ainda é realizada com base no peso corporal (PC) ou no rendimento (peso da carcaça), não havendo a devida valorização dos componentes nãocarcaça, proporcionando perdas econômicas para os produtores e dificultando o retorno do capital investido.

Com a intensificação da produção de carcaças, obviamente, serão incrementadas as quantidades dos componentes não-carcaça, que deverão receber um destino adequado pela indústria da carne ovina ou por outros segmentos da cadeia produtiva. Destes componentes, por exemplo, a pele tem sido largamente utilizada, também mais valorizada, e, quando devidamente processada e manufaturada pela indústria calçadista e vestuária, tem agregado valores que superam com grande vantagem o preço do animal que a originou.

Por outro lado, quantidades expressivas de componentes não-carcaça podem ser aproveitadas para o consumo humano em pratos típicos da culinária regional, como alguns órgãos e vísceras. Gatenby (1986) relata o aproveitamento desses componentes na alimentação humana em várias partes dos trópicos e subtrópicos.

No Nordeste brasileiro, é comum a utilização de vísceras (rúmen, retículo, omaso, abomaso e intestino delgado) e alguns órgãos (pulmões, coração, fígado, baço, rins e língua), além de outros componentes - sangue, omento, diafragma, cabeça e patas - para a preparação de pratos tradicionais como o sarapatel e a "buchada", o que também foi reportado por Costa et al. (2003), Madruga (2003) e Silva Sobrinho (2003). Esses componentes passam por um processo de limpeza e lavagem, são pré-cozidos, resfriados e comercializados em conjunto a preço médio de R \$3,90/kg. Silva Sobrinho (2001) reporta que essa comercialização apresenta fonte adicional de renda, que pode contribuir com parte das despesas no processo de abate.

Com relação ao valor nutritivo, alguns componentes têm valores comparáveis ao da carne, como a proteína, que é de alto valor biológico variando de 17 a 20\% de proteína bruta (Riley et al., 1989; Lawrie, 2005), além de serem excelentes fontes de ferro e fósforo (Madruga, 2003).

Os demais componentes (subprodutos) não utilizados na alimentação humana têm potencial de agregar valor se utilizados pela indústria de farinhas de carne, que são adicionadas às rações de aves, suínos e animais linha pet (cães e gatos).

Portanto, a qualidade do animal vivo não depende somente do rendimento de carcaça e de seus cortes, mas também da proporção e qualidade dos demais componentes do PC, sendo necessária a valorização desses componentes para que a comercialização seja justa para os produtores que buscam a qualidade total, além de beneficiar os consumidores, tanto pelo menor preço como pela melhoria no aspecto sanitário (Osório et al., 2002).

Este trabalho foi realizado com o objetivo de avaliar o efeito dos níveis de concentrado sobre os pesos e rendimentos dos componentes não-carcaça de ovinos Morada Nova em confinamento.

\section{Material e Métodos}

O trabalho foi conduzido no galpão de confinamento do Setor de Caprino-ovinocultura do Departamento de Zootecnia da Universidade Federal Rural de Pernanbuco, localizada em Recife-PE, situada na microrregião fisiográfica do Litoral Mata, pertencente à Região Metropolitana do Recife.

Trinta e dois borregos da raça Morada Nova, variedade vermelha, machos castrados, com idade média de 8,11 $\pm 1,15$ meses de idade, peso inicial de 19,67 $\pm 2,97 \mathrm{~kg}$ e peso ao abate (PCA) de 30,0 kg, foram confinados em baias individuais $(1,0 \times 2,8 \mathrm{~m})$ com $0,80 \mathrm{~m}$ do piso cimentado (local do cocho) e 2,0 m em piso de chão batido, providas de comedouros e bebedouros, onde receberam as dietas experimentais. Os animais foram pesados, identificados, tratados contra ecto e endoparasitas e vacinados contra clostridioses. As pesagens ocorreram a cada sete dias, com jejum prévio, do início do experimento até o abate. Realizaram-se algumas pesagens extras para os animais que apresentaram peso corporal próximo ao peso de abate.

As dietas experimentais continham 15,91 a 18,35\% de PB e foram formuladas com feno moído de capim-tifton 85 (Cynodon dactylon) e diferentes níveis de concentrado (20, 40, 60 e 80\%), composto de milho e farelo de soja e óleo vegetal. Além desses ingredientes, utilizaram-se mistura mineral, calcário calcítico e bicarbonato de sódio (Tabela 1). A dieta de maior nível de concentrado foi formulada de acordo com o NRC (1985), para atender às exigências nutricionais de animais com 20 kg PC e ganho diário de $250 \mathrm{~g} / \mathrm{animal} / \mathrm{dia}$.

Ao atingirem, em média, $32 \mathrm{~kg}$ de peso corporal, os animais foram pesados, obtendo-se assim o peso corporal final (PCF), e submetidos ao jejum de sólidos por 16 horas. Decorrido esse tempo, os animais foram novamente pesados para obtenção do peso ao abate. No momento do abate, os animais foram insensibilizados, por atordoamento, na região atla-occipital, seguido de sangria por quatro minutos, através da seção da carótida e jugular. O sangue foi recolhido em recipiente previamente tarado, para posterior pesagem. 
Após a esfola e evisceração, foram retiradas a cabeça (secção na articulação atla-occipital) e as patas (secção nas articulações carpo e tarso-metatarsianas), registrando-se a seguir os pesos das carcaças quentes (PCQ), incluídos rins e gordura pélvica + renal, que foram retirados e pesados após o resfriamento das carcaças por 24 horas.

Os componentes não-carcaça foram constituídos por órgãos (língua, pulmões + traquéia, coração, fígado, vesícula biliar cheia, pâncreas, timo, rins, baço, diafragma, testículos + pênis, bexiga + glândulas anexas), vísceras (esôfago, rúmen, retículo, omaso, abomaso e intestinos delgado e grosso) e subprodutos (sangue, pele, cabeça, extremidades e depósitos adiposos: gorduras omental, mesentérica, pélvica + renal e gordura ligada ao intestino grosso), conforme esquema proposto por Silva Sobrinho (2001). Os componentes do trato gastrintestinal (TGI) foram pesados cheios e, logo após, esvaziados, lavados e novamente pesados, para determinação do conteúdo do TGI. O peso do corpo vazio (PCVZ) foi obtido através da diferença entre o peso de abate e do conteúdo gastrintestinal.

O delineamento experimental utilizado foi o de blocos casualizados, com quatro tratamentos e oito repetições, sendo os blocos formados de acordo com o peso inicial dos animais.

Além da análise de variância, foi realizada análise de regressão, em função dos níveis de concentrado na dieta. Os critérios utilizados para a escolha das equações foram o comportamento biológico, o coeficiente de determinação $\left(r^{2}\right)$ e a significância, para os parâmetros de regressão, obtida pelo teste "t-Student", para os níveis de 1 e 5\% de probabilidade. As análises estatísticas foram realizadas com auxílio computacional do programa SAEG (UFV, 2001).

\section{Resultados e Discussão}

Verifica-se efeito linear crescente $(\mathrm{P}<0,05)$ do plano nutricional sobre o ganho de peso diário, com valores de 0,089; 0,134; 0,168 e 0,224 kg/dia, para os animais alimentados com 20, 40, 60 e 80\% de concentrado (Tabela 2). No entanto, dos animais que receberam $80 \%$ de concentrado, três $(37,5 \%)$ apresentaram acidose ruminal, com o aparecimento de sinais clínicos (inapetência, atonia ruminal, aumento da freqüência respiratória e diarréia) nos primeiros oito dias de confinamento. Isto exigiu a administração oral de solução saturada de bicarbonato de sódio (50 g/100 mL de água/animal) durante três dias consecutivos e inclusão desse tamponante na formulação do concentrado.

O tempo de permanência dos animais no confinamento (123,37; 86,62; 75,25 e 52,50 dias) decresceu linearmente $(\mathrm{P}<0,05)$ à medida que foi oferecida maior quantidade de concentrado na dieta, antecipando a idade ao abate em 70,87 dias, no maior nível de concentrado.

Houve efeito significativo $(\mathrm{P}<0,05)$ para o peso do corpo vazio (PCVZ) e o conteúdo do trato gastrintestinal

Tabela 1 - Composição em ingredientes e nutricional das dietas experimentais (\%MS)

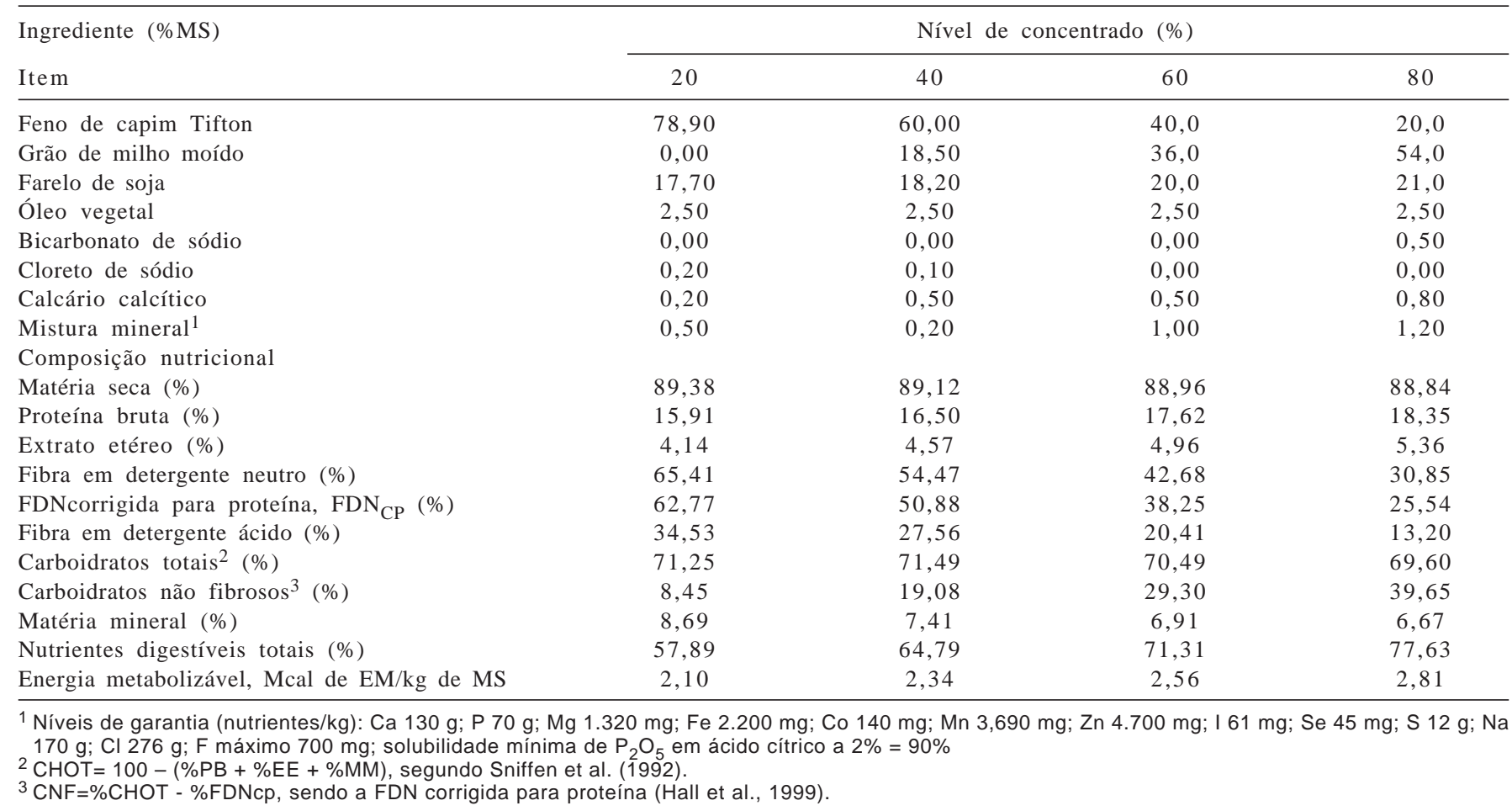


(TGI). O peso do corpo vazio foi crescente em função dos níveis de concentrado, com valores de 25,12; 25,69; 25,87 e 26,82 kg para 20, 40, 60 e 80\% de concentrado, respectivamente (Tabela 2). Estes valores estão relacionados ao menor conteúdo do TGI (5,80; 5,47; 4,80 e 4,16 kg), que foi decrescente quando os níveis de concentrado se elevaram na dieta. As dietas com 20 e $40 \%$ de concentrado, com maiores percentuais de fibra em detergente neutro (65,41 e 54,47\%; Tabela 1) e, portanto, menos digestíveis, passaram mais tempo no TGI durante o período de jejum, influenciando a tomada do peso corporal imediatamente anterior ao abate. Segundo Osório et al. (2002), o conteúdo digestivo apresenta variações que dependem da natureza do alimento, da duração do jejum e do desenvolvimento do trato digestivo, que dependerá da idade do animal e de seu histórico nutricional. Mahgoub et al. (2000) também verificaram que os ovinos alimentados com 40, 60 e $80 \%$ de concentrado apresentaram menores conteúdos do TGI $(4,20 ; 3,13$ e $3,70 \mathrm{~kg}$ ), respectivamente. Haddad \& Husein (2004) reportam que os cordeiros alimentados com $40 \%$ de concentrado tiveram, em média, $1,2 \mathrm{~kg}$ a mais de conteúdo do trato gastrintestinal em relação aos animais alimentados com dietas de $85 \%$ de concentrado.

Constata-se também a representabilidade dos componentes não-carcaça sobre o peso do corpo vazio (PCVZ), que chega a valores de 11,$96 ; 12,08 ; 12,24 ; 12,91 \mathrm{~kg}$, quando o peso da carcaça quente é descontado do PCVZ, equivalendo a 46,81; 47,02; 47,31 e 48,14\% (Tabela 2). Osório et al. (2002) recomendam que, na comercialização que tenha como princípio valorizar a qualidade total do animal, deve-se considerar o "quinto quarto", e não somente a carcaça quente ou PC.

Observa-se (Tabela 3) efeito linear crescente apenas para os pesos do fígado e da vesícula biliar, à medida que aumentaram os níveis de concentrado nas dietas. Os pesos do fígado foram de 0,$497 ; 0,565 ; 0,566$ e $0,653 \mathrm{~kg}$, o que corresponde a 1,97; 2,20; 2,18 e 2,43\% em relação ao peso do corpo vazio (PCVZ). Já a vesícula biliar apresentou pesos de 9,0; 14,0; 20,0 e 33,0 g. O fígado é importante para os vários processos metabólicos, com participação ativa no metabolismo energético e protéico dos animais, a exemplo da captação de cerca de $80 \%$ do propionato que passa pelo sistema portal, para a conversão em glicose (Van Soest, 1994) e da captação de amônia e conversão em uréia, além de síntese e degradação de aminoácidos (Lobley et al., 2000; Kozloski, 2002) e, ainda, síntese de ácidos biliares (Argenzio, 1996). Portanto, o aumento dos níveis de concentrado, os quais elevaram os teores de energia metabolizável das dietas, além de outros nutrientes (Tabela 1), estimulou o desenvolvimento do fígado e da vesícula biliar, o que não ocorreu com demais órgãos, sugerindo que os pesos de língua, pulmões + traquéia, coração, baço, pâncreas, diafragma, aparelho reprodutivo, timo e rins estão mais relacionados ao peso corporal e à maturidade dos animais.

Haddad \& Husein (2004) verificaram que o peso do fígado aumentou de 0,471 para 0,609 $\mathrm{kg}$, quando os ovinos Awassi foram alimentados com dietas contendo 40 e $85 \%$ de concentrado, respectivamente. Silva Sobrinho et al. (2003) observaram que animais abatidos aos $34 \mathrm{~kg}$ PC recebendo $70 \%$ de concentrado apresentaram pesos para o fígado de 0,680 e 0,534 kg para os animais que receberam dieta com $50 \%$ de concentrado.

Alves et al. (2003) não encontraram efeito do nível de energia metabolizável para o aparelho respiratório, coração, fígado, rins e baço. Furusho-Garcia et al. (2003) também não verificaram diferenças significativas para pesos absolutos do coração, pulmões, fígado e pâncreas, nos genótipos Texel× Bergamácia, Texel× Santa Inês e Santa Inês puros.

Tabela 2 - Pesos corporais e do conteúdo do trato gastrintestinal (CTGI) de ovinos Morada Nova, em função dos níveis de concentrado na dieta

\begin{tabular}{|c|c|c|c|c|c|c|c|c|}
\hline Item & \multicolumn{4}{|c|}{ Nível de concentrado (\%) } & CV (\%) & Regressão & $\mathrm{P}$ & $r^{2}$ \\
\hline PC inicial, kg & 20,37 & 19,42 & 19,0 & 19,92 & - & - & & \\
\hline Idade inicial, dias & 247,5 & 251,4 & 234,0 & 240,2 & - & - & - & - \\
\hline Dias de confinamento & 123,37 & 86,62 & 75,25 & 52,50 & 34,58 & $\hat{\mathrm{Y}}=140,438-1,12 \mathrm{C}$ & 0,000 & 0,96 \\
\hline Ganho de peso diário, kg & 0,089 & 0,134 & 0,168 & 0,224 & 28,59 & $\hat{\mathrm{Y}}=0,044331+0,0021982 \mathrm{C}$ & 0,000 & 0,99 \\
\hline Peso de carcaça quente, kg & 13,36 & 13,61 & 13,63 & 13,91 & 5,78 & $\hat{\mathrm{Y}}=13,62 \mathrm{~ns}$ & - & \\
\hline Conteúdo do TGI, kg & 5,80 & 5,47 & 4,80 & 4,16 & 21,96 & $\hat{Y}=6,45427-0,0279098 C$ & 0,003 & 0,98 \\
\hline
\end{tabular}

$\mathrm{C}=$ Nível de concentrado

$\mathrm{P}=$ Nível de significância das equações a 1 e 5\% de probabilidade pelo teste "t". ns - não-significativo. 
A relação peso total dos órgãos (PTO):peso ao abate (PCA), foi significativa $(\mathrm{P}<0,05)$ e evidenciou valores de 4,$95 ; 5,52 ; 5,46$ e 5,80\%, quando as proporções de concentrado se elevaram nas dietas, ao passo que os pesos totais de órgãos (PTO) e a relação PTO:peso do corpo vazio (PCVZ) não foram afetados $(\mathrm{P}>0,05)$ pelos tratamentos. Porém, a tomada da porcentagem do PTO em função do PCA pode ter sido subestimada, pois no PCA está incluído o peso do conteúdo gastrintestinal, o qual não é um componente do PC, ficando, portanto, a relação PTO:PCVZ uma medida mais confiável para essa avaliação.

Houve efeito $(\mathrm{P}<0,05)$ do nível de concentrado sobre os pesos do omaso e intestino delgado (Tabela 4). As demais vísceras (rúmen-retículo, abomaso e intestino grosso) não foram influenciadas $(\mathrm{P}>0,05)$ pelo plano nutricional. Observa-se que o aumento dos níveis de concentrado na dieta promoveu redução nos pesos do omaso (0,089; 0,070; 0,057 e 0,058 kg), fato relacionado ao teor de FDN, visto que dietas com maiores percentuais desse constituinte da parede celular (20 e $40 \%$ de concentrado) podem, segundo Valdés et al. (2000), apresentar maior tempo de retenção no rúmen-retículo, o que também ocorre no omaso, estimulando o desenvolvimento da musculatura e crescimento das suas lâminas para manter o fluxo omasal (Lyford Jr., 1993). Essa redução no peso do omaso pelos animais que consumiram dietas com maiores teores de concentrado (60 e $80 \%$ ) remete à classificação de Hofmann (1993) de que animais seletores de

Tabela 3 - Peso dos órgãos de ovinos Morada Nova em função dos níveis de concentrado na dieta

\begin{tabular}{|c|c|c|c|c|c|c|c|c|}
\hline Órgão & \multicolumn{4}{|c|}{ Nível de concentrado (\%) } & CV (\%) & Regressão & $\mathrm{P}$ & $r^{2}$ \\
\hline Língua (kg) & 0,094 & 0,104 & 0,089 & 0,092 & 18,92 & $\hat{\mathrm{Y}}=0,095 \mathrm{~ns}$ & - & - \\
\hline Coração (kg) & 0,128 & 0,131 & 0,134 & 0,143 & 15,34 & $\hat{\mathrm{Y}}=0,134 \mathrm{~ns}$ & - & - \\
\hline Baço (kg) & 0,046 & 0,048 & 0,059 & 0,053 & 32,24 & $\hat{\mathrm{Y}}=0,052 \mathrm{~ns}$ & - & - \\
\hline Pâncreas (kg) & 0,056 & 0,061 & 0,055 & 0,055 & 0,057 & $\hat{\mathrm{Y}}=0,057 \mathrm{~ns}$ & - & - \\
\hline Diafragma $(\mathrm{kg})$ & 0,118 & 0,127 & 0,130 & 0,133 & 12,62 & $\hat{\mathrm{Y}}=0,127 \mathrm{~ns}$ & - & - \\
\hline Aparelho reprodutivo $(\mathrm{kg})^{1}$ & 0,216 & 0,305 & 0,246 & 0,254 & 59,97 & $\hat{\mathrm{Y}}=0,255 \mathrm{~ns}$ & - & - \\
\hline Timo (kg) & 0,053 & 0,054 & 0,051 & 0,60 & 42,34 & $\hat{\mathrm{Y}}=0,054 \mathrm{~ns}$ & - & - \\
\hline Rins (kg) & 0,084 & 0,079 & 0,084 & 0,090 & 9,31 & $\hat{\mathrm{Y}}=0,084 \mathrm{~ns}$ & - & - \\
\hline
\end{tabular}

$\mathrm{C}=$ Nível de concentrado.

1 Somatório dos pesos dos testículos, pênis, bexiga e glândulas anexas.

$\mathrm{P}=$ Nível de significância das equações a 1 e $5 \%$ de probabilidade pelo teste " $\mathrm{t}$ ".

Tabela 4 - Peso das vísceras vazias de ovinos Morada Nova em função dos níveis de concentrado na dieta

\begin{tabular}{|c|c|c|c|c|c|c|c|c|}
\hline \multirow[t]{2}{*}{ Víscera } & \multicolumn{4}{|c|}{ Nível de concentrado (\%) } & \multirow[b]{2}{*}{ CV (\%) } & \multirow[b]{2}{*}{ Regressão } & \multirow[b]{2}{*}{$\mathrm{P}$} & \multirow[b]{2}{*}{$\mathrm{r}^{2}$} \\
\hline & 20 & 40 & 60 & 80 & & & & \\
\hline Esôfago, kg & 0,059 & 0,056 & 0,055 & 0,052 & 19,35 & $\hat{\mathrm{Y}}=0,055^{\mathrm{ns}}$ & - & - \\
\hline Rúmen-retículo, kg & 0,717 & 0,630 & 0,652 & 0,665 & 10,09 & $\hat{\mathrm{Y}}=0,666 \mathrm{~ns}$ & - & - \\
\hline Omaso, kg & 0,089 & 0,070 & 0,057 & 0,058 & 15,20 & $\hat{\mathrm{Y}}=0,0949937-0,000519188 \mathrm{C}$ & 0,000 & 0,84 \\
\hline Abomaso, kg & 0,140 & 0,133 & 0,128 & 0,135 & 12,55 & $\hat{\mathrm{Y}}=0,134^{\mathrm{ns}}$ & - & - \\
\hline Intestino delgado, kg & 0,460 & 0,564 & 0,582 & 0,650 & 15,23 & $\hat{\mathrm{Y}}=0,417625+0,00293469 \mathrm{C}$ & 0,000 & 0,93 \\
\hline Intestino grosso, kg & 0,377 & 0,399 & 0,399 & 0,464 & 25,47 & $\hat{\mathrm{Y}}=0,410 \mathrm{~ns}$ & - & - \\
\hline Total de vísceras, kg & 1,844 & 1,853 & 1,875 & 2,027 & 12,96 & $\hat{\mathrm{Y}}=1,900 \mathrm{~ns}$ & - & - \\
\hline Vísceras: PCA, \% & 5,96 & 5,94 & 6,09 & 6,54 & 12,09 & $\hat{\mathrm{Y}}=6,13 \mathrm{~ns}$ & - & - \\
\hline Vísceras: PCVZ, \% & 7,36 & 7,24 & 7,25 & 7,58 & 14,21 & $\hat{\mathrm{Y}}=7,36 \mathrm{~ns}$ & - & - \\
\hline
\end{tabular}

$\mathrm{C}=$ Nível de concentrado.

$\mathrm{P}=$ Nível de significância das equações a 1 e $5 \%$ de probabilidade pelo teste " $\mathrm{t}$ ". ns - não significativo. 
concentrado apresentam omaso menos desenvolvido que os consumidores de forragem.

McLeod \& Baldwin (2000) também verificaram redução no peso do omaso de cordeiros alimentados com $75 \%$ de concentrado na dieta em relação aos que receberam $75 \%$ de forragem. Rosa et al. (2002) reportaram que o rúmen-retículo, omaso, abomaso e intestino delgado e grosso apresentaram crescimento heterogônico tardio ( $\mathrm{b}>1$ ), o que contribui para redução do rendimento de carcaça.

Os pesos de intestino delgado foram crescentes em função dos níveis de concentrado $(0,460 ; 0,564 ; 0,582$ e $0,650 \mathrm{~kg}$ ). As dietas com maiores níveis de concentrado, mais energéticas e digestíveis, promoveram o aumento de comprimento e, conseqüentemente, do peso dessa víscera, como forma de ampliar a área de digestão e absorção de nutrientes. Van Soest (1994) reporta que, nos ruminantes, somente pequenas quantidades de açúcares, ácidos graxos e amido escapam do rúmen para o intestino delgado, e a principal atividade dessa víscera é a absorção de aminoácidos.

Furusho-Garcia et al. (2003) relataram pesos de intestino delgado e grosso de 0,$583 ; 0,589 ; 0,564$ kg e 0,$428 ; 0,455$; 0,399 para ovinos alimentados com dietas sem casca de café, casca de café in natura e casca de café tratada com uréia, respectivamente. Nesse mesmo estudo, os ovinos da raça Santa Inês apresentaram pesos de omaso, abomaso, intestino delgado e grosso, respectivamente, de 0,058; 0,138; 0,537 e 0,344 kg, que são muito próximos aos dos ovinos Morada Nova avaliados nesta pesquisa.

Os pesos totais das vísceras, a relação vísceras:PCA e vísceras:PCVZ não foram influenciados $(\mathrm{P}>0,05)$ pela proporção de concentrado nas dietas. As vísceras totais, em termos absolutos, apresentaram pesos de 1,844; 1,853; 1,875 e 2,027 kg. A relação vísceras:PCA foi de 5,96; 5,94; 6,09 e 6,54\%, enquanto a relação vísceras:PCVZ, de 7,6; 7,24; 7,25 e 7,58\%, para os níveis de 20, 40, 60 e $80 \%$ de concentrado, respectivamente.

Com relação aos subprodutos (Tabela 5), houve efeito $(\mathrm{P}<0,05)$ dos níveis de concentrado apenas para o sangue, as patas e a pele. A cabeça, os depósitos adiposos e suas relações com o PCA e PCVZ não sofreram influência ( $P>0,05)$ das dietas, provavelmente pela semelhança entre os pesos ao abate. Resultados similares foram encontrados por Tonetto et al. (2004).

Siqueira et al. (2001) verificaram o efeito do peso de abate nos pesos dos diversos componentes não-carcaça de ovinos abatidos aos 28, 32, 36 e $40 \mathrm{~kg}$, destacando o peso da pele, que foi maior nas fêmeas. Bueno et al. (2000) também reportam efeito linear crescente para os pesos do sangue, pele, cabeça, patas, gordura mesentérica e perirenal, com o aumento do PC de ovinos Suffolk.

Segundo Rosa et al. (2002), as patas são de crescimento precoce $(b<1)$, enquanto a pele e a cabeça, de crescimento isogônico, pois crescem com a mesma velocidade do corpo $(b=1)$. Por outro lado, Roque et al. (1999) encontraram desenvolvimento proporcional ao PC (isogônico) para as patas e pele de ovinos lanados, enquanto o crescimento da cabeça foi precoce para as raças Romney Marsh e Texel.

Desses subprodutos, a pele tem sido o componente mais valorizado comercialmente, além da grande demanda pelos curtumes, que atualmente trabalham em ociosidade pela sua baixa oferta. Ressalta-se que as peles dos ovinos deslanados são consideradas de excelente qualidade,

Tabela 5 - Peso dos subprodutos de ovinos Morada Nova em função dos níveis de concentrado na dieta

\begin{tabular}{|c|c|c|c|c|c|c|c|c|}
\hline \multirow[t]{2}{*}{ Subproduto } & \multicolumn{4}{|c|}{ Nível de concentrado (\%) } & \multirow[b]{2}{*}{ CV (\%) } & \multirow[b]{2}{*}{ Regressão } & \multirow[b]{2}{*}{$\mathrm{P}$} & \multirow[b]{2}{*}{$r^{2}$} \\
\hline & 20 & 40 & 60 & 80 & & & & \\
\hline Sangue, kg & 1,258 & 1,363 & 1,295 & 1,597 & 17,74 & $\hat{\mathrm{Y}}=1,14091+0,0047509 \mathrm{C}$ & 0,020 & 0,65 \\
\hline Cabeça, kg & 1,609 & 1,633 & 1,573 & 1,618 & 6,35 & $\hat{\mathrm{Y}}=1,608 \mathrm{~ns}$ & & \\
\hline Patas, kg & 0,607 & 0,623 & 0,620 & 0,692 & 9,00 & $\hat{\mathrm{Y}}=0,573313+0,00125719 \mathrm{C}$ & 0,009 & 0,72 \\
\hline Mesentério, kg & 0,358 & 0,465 & 0,439 & 0,486 & 30,66 & $\hat{\mathrm{Y}}=0,437 \mathrm{~ns}$ & - & - \\
\hline Renal + pélvica, kg & 0,848 & 0,759 & 0,637 & 0,865 & 31,58 & $\hat{\mathrm{Y}}=0,777^{\mathrm{ns}}$ & - & - \\
\hline $\mathrm{GLIG}^{1}, \mathrm{~kg}$ & 0,151 & 0,159 & 0,181 & 0,204 & 32,06 & $\hat{\mathrm{Y}}=0,174 \mathrm{~ns}$ & - & - \\
\hline Gordura total, kg & 2,114 & 2,070 & 2,096 & 2,209 & 29,93 & $\hat{\mathrm{Y}}=2,122 \mathrm{~ns}$ & - & - \\
\hline Gordura total:PCA, \% & 6,85 & 6,64 & 6,90 & 7,12 & 31,23 & $\hat{\mathrm{Y}}=6,88 \mathrm{~ns}$ & - & - \\
\hline
\end{tabular}

C = Nível de concentrado.

${ }^{1}$ Gordura ligada ao intestino grosso.

$\mathrm{P}=$ Nível de significância das equações a 1 e $5 \%$ de probabilidade pelo teste "t". ns - não-significativo. 
exemplo da raça Morada Nova, devido à maior espessura e maior quantidade de fibras de colágeno, distribuídas nas camadas reticulares, e à pequena quantidade de componentes não-estruturais, como glândulas sebáceas, sudoríparas e folículos pilosos (Jacinto, 2004), despertando o interesse da indústria vestuária e calçadista (Gonzaga Neto, 2003). Vários autores reportam que o aumento do PC ao abate acarreta maiores pesos e proporções de pele, principalmente nas raças ovinas lanadas (Pires et al., 2000; Siqueira et al., 2001; Bueno et al., 2000).

Verifica-se, em termos absolutos, que houve alta deposição de gordura interna nos animais, independentemente dos níveis de concentrado (Tabela 5). Os tecidos adiposos omento, mesentério, perirenal e a gordura ligada à porção final do intestino grosso apresentaram médias de 0,733 ; 0,437; 0,777 e 0,174 kg, respectivamente. Essas deposições de gordura em ovinos tropicais atuam como reservas energéticas para serem mobilizadas durante o período de escassez de alimentos. Ermias et al. (2002). Lawrence \& Fowler (2002) complementam que essas deposições também ocorrem com a maturidade.

Vale ressaltar que esses tecidos adiposos não têm valorização comercial e, também, não são utilizados para consumo humano, exceto parte do omento, quando da preparação de algumas iguarias da região Nordeste, até porque apresentam altos valores de ácidos graxos saturados (Banskalieva et al., 2000). Calculando-se o produto da média da gordura total (2,122 kg), constante na Tabela 5, pelo número de animais abatidos neste estudo, obtêm-se aproximadamente $68,0 \mathrm{~kg}$ de gordura que não foram comercializados. Portanto, torna-se visível a possibilidade de perdas econômicas com o aumento desses tecidos, mesmo que sejam biologicamente importantes para esses animais.

Há necessidade de se encontrarem os pontos de inflexão mais adequados que representem o efeito da maturidade e do plano nutricional sobre o crescimento tecidual dos ovinos da raça Morada Nova. Nesta pesquisa, observou-se efeito linear crescente $(\mathrm{P}<0,05)$ do plano nutricional sobre o ganho de peso diário, como já anteriormente mencionado. Logo, níveis iguais ou superiores a $60 \%$ de concentrado proporcionam maiores ganhos de peso, bem como reduzem o período de confinamento. Entretanto, devem-se contabilizar os custos com a utilização de níveis elevados de concentrado na dieta, bem como prevenir-se contra os problemas de distúrbios metabólicos como a acidose ruminal.

Osório et al. (2002) relataram que a distribuição de gordura segue modelos diferentes de desenvolvimento, sendo que, para cada genótipo, existe uma idade e um peso ótimo de abate, para o qual a proporção de músculo será a máxima; a de osso, a mínima; e a de gordura, suficiente para conferir à carcaça as melhores características de conservação e à carne, as ótimas propriedades organolépticas.

No que concerne aos componentes comestíveis (Tabela 6), observa-se que houve efeito linear crescente $(\mathrm{P}<0,05)$ para os pesos e rendimentos dos miúdos da "buchada", que apresentaram valores de 4,489; 4,602; 4,750 e 5,055 kg e 14,51; 14,75; 15,50 e 16,29\% em relação ao PCA (peso ao abate), mas não em relação ao peso do corpo vazio ( $\mathrm{P}>0,05)$, em função dos níveis de concentrado na dieta, respectivamente. Para os outros componentes cabeça + patas, os níveis de concentrado não influenciaram em termos de peso e rendimentos em relação ao PCA e PCVZ.

Para que a cabeça e as patas sejam comercializadas em conjunto com os miúdos da "buchada”, estes passam por um processo de limpeza no qual são retirados em torno de $50 \%$ de componentes não-comestíveis, como a pele da cabeça e das patas, orelhas, olhos, todo o chanfro e maxilares superior e inferior, além do pré-cozimento a que são submetidos. Portanto, somando-se média dos miúdos da "buchada" $(4,724 \mathrm{~kg})$ com a da cabeça + patas (assumindo-se que na limpeza desses dois componentes há perda de $50 \%$ do peso médio: 2,244 kg - 50\% = 1,122 kg),

Tabela 6 - Rendimento de componentes comestíveis de ovinos Morada Nova em função dos níveis de concentrado na dieta

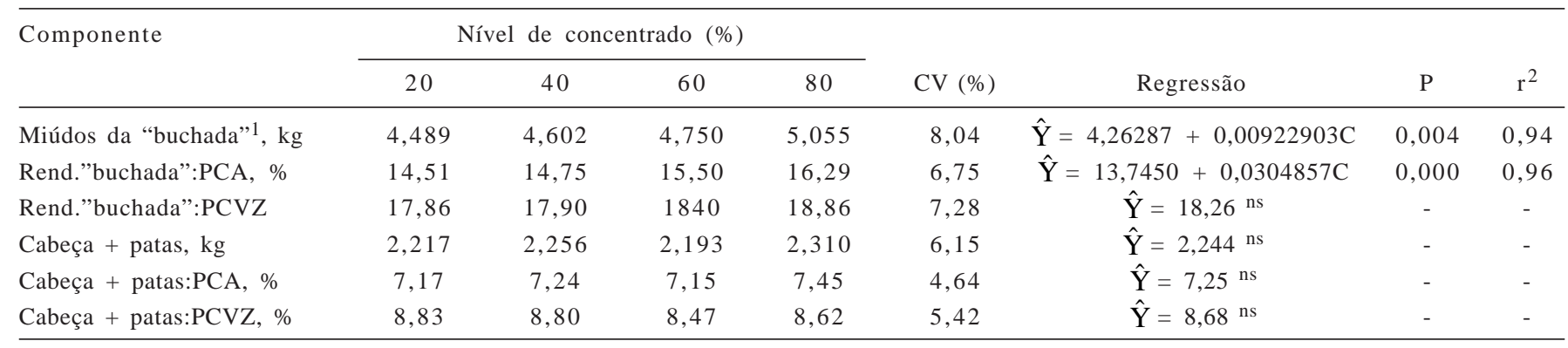

$\mathrm{C}=$ Nível de concentrado.

${ }^{1}$ Somatório dos pesos do sangue, fígado, rins, pulmões, baço, língua, coração, omento, rúmen-retículo, omaso, intestino delgado

$\mathrm{P}=$ Nível de significância das equações a 1 e $5 \%$ de probabilidade pelo teste " $\mathrm{t}$ ".

ns - não significativo. 
seriam obtidos em torno de 5,846 kg para serem comercializados a preço médio de $\mathrm{R} \$ 3,90 / \mathrm{kg}$, como anteriormente mencionado. Esse peso representaria aproximadamente 18,9 e $22,6 \%$ de rendimento total em relação às médias do PCA e PCVZ, respectivamente. Karim et al. (2002) relataram valores totais de vísceras comestíveis de 8,5 e 10,4 kg para ovinos Malpura e Awassi $\times$ Malpura, sendo essa diferença devida ao peso de abate.

Pode-se inferir que o aproveitamento desses componentes, além do aspecto nutricional, é importante fonte adicional de renda que deveria ser considerada no momento da comercialização dos animais, para que o produtor fosse melhor remunerado. Por outro lado, há necessidade de estudos visando à melhoria da qualidade microbiológica desses componentes da "buchada", bem como formas de processamento, conservação e apresentação do produto, para que possa agregar mais valor comercial e oferecer mais garantia em termos de segurança alimentar.

\section{Conclusões}

O aumento dos níveis de concentrado na dieta contribuiu para elevar o peso do corpo vazio e reduzir o conteúdo gastrintestinal dos ovinos Morada Nova.

Maiores níveis de concentrado elevaram os pesos de fígado, vesícula biliar, omaso, intestino delgado, sangue, patas e pele e os pesos e rendimentos dos miúdos da "buchada".

Independentemente dos níveis de concentrado utilizados, os pesos e rendimentos de alguns órgãos, vísceras e subprodutos como a gordura visceral, foram altos, com valores que refletem diretamente em menores pesos e rendimentos da carcaça dos ovinos Morada Nova confinados, indicando que se deve avaliar a relação custos da maximização de uso de concentrado:valorização dos componentes não-carcaça.

\section{Agradecimento}

Ao Conselho Nacional de Pesquisa e Desenvolvimento (CNPq), pela concessão da bolsa de Doutorado.

\section{Literatura Citada}

ALVES, K.S.; CARVALHO, F.F.R.; FERREIRA, M.A. et al. Níveis de energia em dietas para ovinos Santa Inês: características de carcaça e constituintes corporais. Revista Brasileira de Zootecnia, v.32, n.6, p.1927-1936, 2003 (supl. 2).

ARGENZIO, R.A. Digestão, absorção e metabolismo: funções gerais do trato gastrintestinal e seu controle e integração. In: SWENSON, M.J.; REECE, W.O. (Eds.) Dukes: Fisiologia dos animais domésticos. 11.ed. Rio de Janeiro: Guanabara Koogan, 1996. p.297-306.

BANSKALIEVA, V.; SAHLU, T.; GOETSCH, A.L. Fatty acid composition of goat muscles and fat depots: a review. Small Ruminant Research, v.37, p.255-268, 2000.

BUENO, M.S.; CUNHA, E.A.; SANTOS, L.E. et al. Características de carcaça de cordeiros Suffolk abatidos em diferentes idades. Revista Brasileira de Zootecnia, v.29, n.6, p.1803-1810, 2000.

COSTA, R.G.; MEDEIROS, A.N.; CARVALHO, F.F.R. Perspectivas e desafios para produção de carne caprina no Brasil. In: REUNIÃO ANUAL DA SOCIEDADE BRASILEIRA DE ZOOTECNIA, 40., 2003, Santa Maria. Anais... Santa Maria, Sociedade Brasileira de Zootecnia/Gmosis, 2003. (CD-ROM).

ERMIAS, E.; YAMI, A.; REGE, J.E.O. Fat deposition in tropical sheep as adaptive attribute to periodic feed flutuaction. Journal of Animal Breeding and Genetics, v.119, p.235-246, 2002.

FURUSHO-GARCIA, I.F.; PÉREZ, J.R.O.; OLIVEIRA, M.V.M Componentes corporais e órgãos internos de cordeiros Texel $\mathrm{x}$ Bergamácia, Texel x Santa Inês e Santa Inês puros, terminados em confinamentos, com casca de café com parte da dieta. Revista Brasileira de Zootecnia, v.32, n.6, p.1992-1998, 2003 (supl. 2).

GATENBY, M.R. Sheep producition in the tropics and subtropics. New York: Longman Inc., 1986. 351p.

GONZAGA NETO, S. Composição corporal, exigências nutricionais e características da carcaça de cordeiros Morada Nova. Jaboticabal: Universidade Estadual Paulista, 2003. 93p. Tese (Doutorado em Zootecnia) - Universidade Estadual Paulista, 2003.

HADDAD, S.G.; HUSEIN, M.Q. Effect of dietary energy density on growth performance and slaughtering characteristics of fattening Awassi lambs. Livestock Production Science, v.87, p.171-177, 2004.

HALL, M.B.; HOOVER, W.H.; JENNINGS, J.P. et al. A method for partitioning neutral detergent soluble carbohydrates. Journal Science Food Agriculture, v.79, p.2079-2086, 1999.

HOFMANN, R.R. Anatomia del conducto gastro-intestinal. In CHURCH, D.C. (Ed.). El rumiante: fisiología digestiva y nutrición. Zaragoza: Acribia, 1993. p.15-46.

JACINTO, M.A.C. Qualidade de peles e couros caprinos e ovinos In: SIMPÓSIO INTERNACIONAL DE CONSERVAÇÃO DE RECURSOS GENÉTICOS: RAÇAS NATIVAS PARA O SEMIÁRIDO, 1., 2004, Recife. Anais... Recife: Universidade Federal Rurak do Pernambuco, 2004. p.172-185.

KARIM, S.A.; SANTRA, A.; VERMA, D.L. Growth, feed conversion efficiency and carcass characteristics of Malpura and Awassi x Malpura crossbred lambs in a hot semi arid enviroment. Asian-Australasian Journal of Animal Science, v.15, n.3, p.377-381, 2002.

KOZLOSKI, G.V. Bioquímica dos ruminantes. Santa Maria: Universidade Federal de Santa Maria, 2002. 140p.

LAWRENCE, T.L.J.; FOWLER, V.R. Growth in farm animals 2.ed. Wallingford: CAB International, 2002. 346p.

LAWRIE, R.A. Ciência da carne. Trad. Jane Maria Rubensam. 6.ed. Porto Alegre: Artmed, 2005. 384p.

LOBLEY, G.E. ; MILANO, G.D.; van der WALT, J.G. The liver: integrator of nitrogen metabolism. In: CRONJÉ, P.B.; BOOMKER, E.A.; HENNING, P.H. et al. (Eds.) Ruminant physiology: digestion, metabolism, growth and reproduction. London: CAB International, 2000. p.149-168.

LYFORD JR., S.J. Crecimento y desarrollo del aparato digestivo de los rumiantes. In: CHURCH, D.C. (Ed.). El rumiante: fisiología digestiva y nutrición. Zaragoza: Acribia, 1993. p.47-68.

MADRUGA, M.S. Fatores que afetam a qualidade da carne caprina e ovina. In: SIMPÓSIO INTERNACIONAL SOBRE CAPRINOS E OVINOS DE CORTE, 2., 2003, João Pessoa. Anais... João Pessoa: EMEPA, 2003. p.417-432. 
MAHGOUB, O.; LU, C.D.; EARLY, R.J. Effects of dietary energy density on feed intake, body weight gain and carcass chemical composition of Omani growing lambs. Small Ruminant Research, v.37, p.35-42, 2000.

McLEOD, K.R.; BALDWIN, R.L. Effects of diet forage:concentrate ratio and metabolizable energy intake on visceral organ growth and in vitro oxidative capacity of gut tissues in sheep. Journal of Animal Science, v.78, p.760-770, 2000.

NATIONAL RESEARCH COUNCIL - NRC. Nutrient requeriments of sheep. 6.ed. Washington, D.C.: National Academy Press, 1985. 99p.

OSÓRIO, J.C.S.; OSÓRIO, M.T.M.; OLIVEIRA, N.M. et al. Qualidade, morfologia e avaliação de carcaças. Pelotas: Universidade Federal de Pelotas, 2002. 194p.

PIRES, C.C.; SILVA, L.F.; FARINATTI, L.H.E. et al. Crescimento de cordeiros abatidos com diferentes pesos. 2. Constituintes corporais. Ciência Rural, v.30, n.5, p.869-873, 2000.

RILEY, R.R.; SAVELL, J.W.; SHELTON, M. et al. Carcass and offal yields of sheep and goats as influenced by market class and breed. Small Ruminant Research, v.2, p.265-272, 1989.

ROQUE, A.P.; OSÓRIO, J.C.S.; JARDIM, P.O. et al. Produção de carne em ovinos de cinco genótipos. 6. Desenvolvimento relativo. Ciência Rural, v.29, n.3, p.549-553, 1999.

ROSA, G.T.; PIRES, C.C.; SILVA, J.H.S. et al. Proporções e coeficientes de crescimento dos não-componentes da carcaça de cordeiros e cordeiras em diferentes métodos de alimentação. Revista Brasileira de Zootecnia, v.31, n.6, p.2290-2298, 2002.

SILVA SOBRINHO, A.G. Aspectos quantitativos e qualitativos da produção de carne ovina. In: REUNIÃO ANUAL DA
SOCIEDADE BRASILEIRA DE ZOOTECNIA, 2001, Piracicaba. Palestras... Piracicaba: Sociedade Brasileira de Zootecnia, 2001. p.425-446.

SILVA SOBRINHO, A.G.; GASTALDI, K.A.; GARCIA, C.A. et al. Diferentes dietas e pesos ao abate na produção de órgãos de cordeiros. Revista Brasileira de Zootecnia, v.32, n.6, p.17921799, 2003 (supl. 1).

SIQUEIRA, E.R.; SIMÕES, C.D.; FERNANDES, S. Efeito do sexo e do peso ao abate sobre a produção de carne de cordeiro. Morfologia da carcaça, peso dos cortes, composição tecidual e componentes não constituintes da carcaça. Revista Brasileira de Zootecnia, v.30, n.4, 1299-1307, 2001.

UNIVERSIDADE FEDERAL DE VIÇOSA - UFV. Sistema de Análises Estatísticas e Genéticas - SAEG. Viçosa, MG: UFV, 2001. 301p.

SNIFFEN, C.J.; O’CONNOR, J.D.; Van SOEST, P.J. et al. A net carbohidrate and protein system for evaluating cattle diets: II. Carbohydrate and protein availability. Journal of Animal Science, v.70, p.3562-3577, 1992.

TONETTO, C.J.; PIRES, C.C.; MÜLLER, L. et al. Rendimentos de cortes da carcaça, características da carne e componentes do peso vivo em cordeiros terminados em três sistemas de alimentação. Revista Brasileira de Zootecnia, v.33, n.1, p.234-241, 2004.

VALDÉS, C.; CARRO, M.D.; RANILLA, M.J. et al. Effect of forage to concentrate ratio in complete diets offered to sheep on voluntary food intake and some digestive parameters. Animal Science, v.70, p.119-126, 2000.

Van SOEST, P.J. Nutritional ecology of the ruminant. 2.ed. Ithaca: Cornell University Press, 1994. 476p. 